\title{
Comparing the Effect of Educational Software and Booklet on Knowledge Level Regarding Labor Pain Management: A Randomized Controlled Clinical Trial
}

\author{
Parastoo Abbasi $^{{ }^{*}}$, Sakineh Mohammad-Alizadeh Charandabi ${ }^{1}$, Mojgan Mirghafourvand ${ }^{1}$
}

\begin{abstract}
Objectives: In all parts of the world, education about pregnancy and childbirth are offered to women as part of routine care. This study aimed to compare the effect of software and booklet on knowledge regarding labor pain management.

Materials and Methods: This randomized controlled clinical trial was conducted on 153 pregnant women referring to healthcare centers of Miandoab city in West Azerbaijan province, Iran in 2015-2016. Participants were assigned into 2 intervention groups (educational software and educational booklet) and the control group. A single face-to-face session was held by the researcher for intervention group on the management of labor pain in 30-34 weeks of pregnancy and booklet and software were presented. The questionnaire of knowledge of labor pain management was completed by the participants before and four weeks after the intervention. Analysis of covariance (ANCOVA) with baseline score adjustment was used to compare the mean score of knowledge between the study groups.

Results: By adjusting the baseline score, the mean score of knowledge after the intervention in both software group (mean difference $=5.5$; CI 95\%: 4.6 to 6.3$)$ and booklet group $(3.4 ; 2.5$ to 4.2$)$ was significantly higher than the control group. Also, the increase in knowledge score in the software group $(2.1 ; 1.2$ to 9.2$)$ was significantly higher than the booklet group.

Conclusion: The results show that both software and booklet are effective in improving maternal knowledge about managing the labor pain and the software is more effective than booklet, thus, it seems that e-learning can be used as replacement for traditional educational methods.

Keywords: Knowledge, Labor pain, Pregnancy software
\end{abstract}

\section{Introduction}

More than $90 \%$ of the stress and anxiety during pregnancy is associated with birth process (1). Labor pain as biological, psychological and social phenomenon, has complex and multiple relationships with many psychological, cultural and racial dimensions and the economic status of human. Therefore, seeking strategies to reduce or eliminate such pain has always been a demand of most mothers and relevant people involved in this domain. Lack of awareness and fear of unknown issues related to pregnancy and childbirth leads to maternal anxiety during this period. As a result of fear and anxiety, stress hormones are increased and may lead to premature delivery, lack of labor progress, low birth weight and fetal hypoxia (2).

Women's access to all health services along with increasing their awareness through education and counseling during pregnancy and childbirth are among important factor in preventing mortality and complications during this period. Increasing knowledge and skills during pregnancy prepares mothers for birth and promotes their health status. Today, education is one of the indispensable elements of human life, and in many parts of the world, education about pregnancy and childbirth, which aims to raise awareness of pregnant women and their partners about childbirth and parenthood, are offered to women as part of routine prenatal care (3).

So far, different educational methods have been applied to educate learners, but problems including lack of expert and experienced trainers, new educational facilities in the region and the possibility to access to modern educational technology as well as the problem related to learners' presence in the classroom setting, led to the development of remote teaching - learning methods and strategies using educational software and technologies $(4,5)$.

In the booklet training method, the learner is provided with knowledge and experience at the same time and is applied more for educated people and this method can be used when there is not sufficient number of trainers. The training booklet is recommended as a teaching method while comparing the effect of face-to-face training and the booklet-based training method on the patient's learning after urinary tract surgeries (6). In another study, although the impact of individual training of health workers was more effective in raising awareness of mothers towards infants' anthropometric changes, the impact of this type of remote training was effective as well (7). The disadvantages of training booklet include lack of infrastructure, limited access to teachers, lack of adequate educational 
content and etc; therefore, to achieve better results, it was recommended to provide the access to suitable software infrastructure (8).

In the e-learning method, the learner can learn educational materials without face-to-face training and even over long distances (9). This type of training, which is the most important application of information technology, is provided in the form of computer-based learning (10). In fact, training healthcare providers along with pamphlets and other educational materials do not always meet different expectation levels of pregnant women and satisfy them (11); however, in multimedia-based education method, people learn how to learn. There is not time and place restriction in this method, and people can use it for self-study at home or other environments and set contents based on their learning schedule. In this method, employed mothers who had no enough time to visit clinics or to receive training offered by health personnel, can learn educational materials without anxiety or stress (12). In a meta-analysis published in 2006, it was shown that e-learning was $6 \%$ or more, more effective than the face to face training in delivering knowledge (13).

Regarding the adoption of e-learning in nulliparous women, Lin's study on satisfaction of pregnant women in Taiwan (14), Huang and colleagues' study on lactating mothers' awareness in the postpartum period (12) and the study of Kuo et al on women's awareness regarding newborns care in Taiwan, showed that computer-based training is more effective than the control group that received only the routine training (15).

Considering the severe effects of pain on the outcomes of labor (2) and the effect of improving the quality of prenatal education on maternal (15) and newborn health as well as the absence of a study on the impact of education on the knowledge about management of labor pain and by comparing two methods of booklet and e-learning, the present study aimed to compare the effect of instructional software and booklet on mothers' knowledge level about the management of labor pain.

\section{Materials and Methods}

Study Type and Participants

The present study was a randomized controlled clinical trial, which was conducted on 153 pregnant women referred to healthcare centers in the city of Miandoab in West Azerbaijan province, Iran in 2015-2016.

Inclusion criteria included a written consent to participate in the study, being literate, aged 18 to 35 years, 30 to 34 weeks pregnancy, nulliparous, singleton pregnancy, access to computers and the ability to use computers and exclusion criteria consisted of any pregnancy complication, a high-risk pregnancy, known natural childbirth contraindications, participation in childbirth preparation classes and tendency to cesarean section.

This study is part of a large study where the sample size was determined based on the variable of labor pain intensity (12). The sample size was calculated 46 people based on the variable of labor pain and by taking into account the $\mathrm{m}_{1}=50.23, \mathrm{~m}_{2}=42.66$ (taking into account the $15 \%$ reduction in labor pain caused by the intervention), $\mathrm{sd}_{1}=$ $\mathrm{sd}_{2}=14.44, \alpha=0.05$ and $\beta=0.2$ ), which 51 people were considered in each group by taking into account the $10 \%$ loss in the final sample size.

\section{Sampling}

Sampling was done in all Miandoab healthcare centers, which included 5 centers.

After the initial selection of participants using convenience sampling, objectives of study were explained to them. They were investigated in terms of having inclusion and exclusion criteria in the case of willingness to participate in the study and if they had the eligibility criteria, the information about the methodology and confidentiality matters was provided. Then, they were voluntarily included in the study and written informed consent was obtained and questionnaires of socio-demographic characteristics and knowledge of labor pain management were filled by participants using self-completed method. The knowledge questionnaire was completed again by the participants 4 weeks after the intervention by participants.

\section{Randomization and Intervention}

Participants were assigned into 3 groups; including receiving training booklet (51 mothers), e-learning (51 mothers) and control groups (51 mothers) using block randomization with 3 and 6 block sizes and allocation ratio of 1: 1: 1 . To conceal the allocation, type of intervention was written on paper and was placed into numbered matte envelopes. The envelopes were opened in order of participant's entry into the study, and type of intervention received by participants was identified. Allocation sequence was performed by a person uninvolved in the selection of samples and analysis of data.

A face-to-face session was held for 30 minutes by the researcher for the participants in both intervention groups and in addition to delivery of the training booklet or educational software and an explanation on how to use them, the educational content was explained to them and they were asked to study the booklet and software until a sufficient mastery was obtained on the educational content of software and booklet. However, the participants were called by the researcher every week to remind them to study the training booklet and software. The electronic software was developed by the Ministry of Health and Medical Education of Iran and the booklet was also prepared with the same educational content by researcher. The content of the training booklet and software was similar and contains situation modification in pregnancy, stretching exercises and breathing, breathing pattern, relaxation and massage. The control group also received the routine education during pregnancy.

\section{Tools and Methods for Data Collection}

Data collection tools included socio-demographic characteristics and knowledge of labor pain management questionnaires, which were completed using self-com- 
pleted method.

Socio-demographic characteristics questionnaire included questions on age, educational level, sufficiency of family income for living expenses per month, place of residence, marital satisfaction, perceived support from a spouse, and support received from the family.

Knowledge questionnaire was a researcher-made questionnaire that its items were designed by the research team based on the educational content. This questionnaire contained 10 questions, each of which has 3 options of 'correct,' 'wrong' and 'I do not know.' Each 'correct' answer was assigned +1 and 'wrong' and 'I don't know' options were assigned 0 score. Scores ranges from 0 to 10 . The validity of the questionnaire was confirmed using content and face validity and its reliability was confirmed using test - retest on 30 pregnant women. The intra-class correlation coeffecient (ICC) was equal to 0.76 and the Cronbach alpha was calculated to be 0.82 .

Data Analysis

The collected data were analyzed using SPSS 20. Kolmogorov-Smirnov test was used to determine the normality of quantitative data. Chi-square, chi-square for trend, Fisher exact and one-way analysis of variance (ANOVA) tests were used to study the homogeneity of intervention and control groups in terms of socio-demographic characteristics. One-way ANOVA and analysis of covariance (ANCOVA) tests with adjusted baseline score were used to compare mean score of knowledge about labor pain management between the study groups, respec- tively before and after the intervention.

\section{Results}

Sampling began from October 2015 and continued until April 2016. A total of 700 were investigated to determine whether they have the eligibility criteria and 547 of them were excluded from the study due to lacking the eligibility criteria. And finally, 153 people (50 people in the training software group, 51 people in the training booklet group and 52 patients in the control group) were entered into the study and were followed up for 4 weeks and completed the questionnaire of knowledge about labor pain management (Figure 1).

There was no statistically significant difference among the 3 groups in terms of socio-demographic characteristics $(P>0.05)$. The socio-demographic characteristics were shown in Table 1.

There was no statistically significant difference among the groups studied in terms of the mean knowledge score before the intervention $(P>0.05)$. Mean \pm standard deviation (SD) knowledge score in the software group increased from $1.6 \pm 0.7$ before the intervention to $9.0 \pm 2.0$ four weeks after the intervention. The same value in the booklet and control groups increased from $1.4 \pm 0.6$ and $1.6 \pm 0.6$ to $6.9 \pm 1.9$ and $3.5 \pm 1.3$, respectively. According to the general linear model and by controlling the baseline value, the post-intervention mean score of knowledge in the software group (5.5: Adjusted mean difference: 5.5; CI 95\%: 4.6 to 6.3$)$ and in the booklet group $(3.4 ; 2.5$ to 4.2) had a statistically significant increase compared to

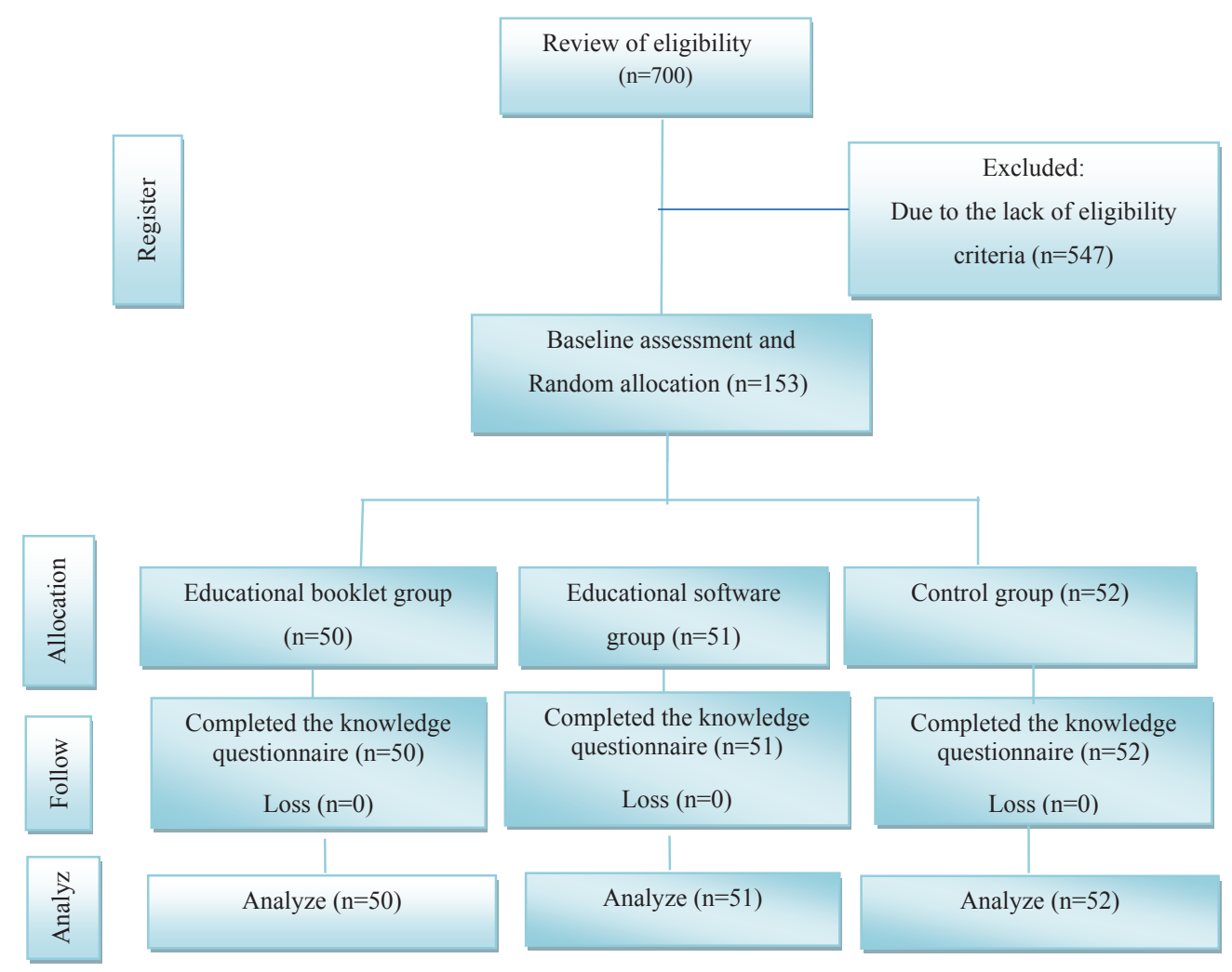

Figure 1. The flowchart of the Participants in the Study. 
Table 1. Comparison of Socio-Demographic Characteristics Between Study Groups

\begin{tabular}{|c|c|c|c|c|}
\hline Variable & $\begin{array}{c}\text { Software }(n=50) \\
\text { No. }(\%)\end{array}$ & $\begin{array}{c}\text { Booklet }(n=51) \\
\text { No. }(\%)\end{array}$ & $\begin{array}{c}\text { Control( } n=52) \\
\text { No. (\%) }\end{array}$ & $P$ Value \\
\hline Age $^{a}$ & $25.5(3.8)$ & $25.9(3.6)$ & $25.1(3.2)$ & $0.543^{b}$ \\
\hline \multicolumn{5}{|l|}{ Education } \\
\hline Secondary & $9(18.0)$ & $7(13.7)$ & $9(17.3)$ & \multirow{4}{*}{$0.819^{c}$} \\
\hline High school & $18(36.0)$ & $20(39.2)$ & $22(42.3)$ & \\
\hline Diploma & $91(38.0)$ & $22(43.1)$ & $20(38.4)$ & \\
\hline University & $4(8.0)$ & $2(3.9)$ & $1(1.9)$ & \\
\hline \multicolumn{5}{|l|}{ Job } \\
\hline Homeworker & $43(86.0)$ & $43(84.3)$ & $43(82.7)$ & \multirow{2}{*}{$0.900^{\circ}$} \\
\hline Practitioner & $7(14.0)$ & $8(15.6)$ & $9(17.3)$ & \\
\hline \multicolumn{5}{|c|}{ Sufficient income for living expenses } \\
\hline Enough & $3(6.0)$ & $3(5.9)$ & $2(3.6)$ & \multirow{3}{*}{$0.916^{c}$} \\
\hline Quite enough & $42(84.0)$ & $45(88.2)$ & $45(86.5)$ & \\
\hline Inadequate & $5(10.0)$ & $3(5.9)$ & $5(9.6)$ & \\
\hline \multicolumn{5}{|l|}{ Home status } \\
\hline Personal & $12(24.0)$ & $8(15.7)$ & $8(15.4)$ & \multirow{4}{*}{$0.933^{c}$} \\
\hline Retired & $22(44.0)$ & $21(41.2)$ & $21(40.4)$ & \\
\hline Your parents house & $2(4.0)$ & $2(3.9)$ & $1(1.8)$ & \\
\hline Spouse's parents house & $14(28.0)$ & $20(39.2)$ & $22(42.3)$ & \\
\hline \multicolumn{5}{|l|}{ Marital satisfaction } \\
\hline Yes & $48(96.0)$ & $48(94.1)$ & $52(100)$ & \multirow{2}{*}{$0.229^{c}$} \\
\hline No & $2(40.0)$ & $3(5.9)$ & $0(0)$ & \\
\hline \multicolumn{5}{|l|}{ Support received of husband } \\
\hline Very much \& much & $41(82.0)$ & $39(76.5)$ & 39 (74.9) & \multirow{3}{*}{$0.815^{d}$} \\
\hline Average & $7(14.0)$ & $10(19.6)$ & $9(17.3)$ & \\
\hline Low \& very low & $2(4.0)$ & $2(3.8)$ & $4(7.7)$ & \\
\hline \multicolumn{5}{|l|}{ Support received of family } \\
\hline Very much \& much & $22(44.0)$ & $22(43.1)$ & $19(36.5)$ & \multirow{3}{*}{$0.294^{d}$} \\
\hline Average & $26(52.0)$ & $28(54.9)$ & 27 (51.9) & \\
\hline Low \& very low & (4.0) 2 & $1(1.9)$ & $6(11.4)$ & \\
\hline
\end{tabular}

${ }^{a}$ The numbers are expressed as number (percent) except for age (mean and standard deviation).

${ }^{\mathrm{b}}$ One-way analysis of variance.

${ }^{\mathrm{c}}$ Chi-square test.

${ }^{\mathrm{d}}$ Chi-square test process

Note: The other jobs were including driver, farmer, carpentry, etc.

the control group. Also, post-intervention mean score of knowledge in the software group $(2.1 ; 1.2$ to 2.9$)$ was significantly higher compared to the booklet group (Table 2).

\section{Discussion}

Adequate and proper training increases mother's knowledge about pregnancy and birth and enables her to use in problem-solving strategies in this regard (16). Effective prenatal education with a focus on raising awareness regarding pregnancy and childbirth process plays an effective role in reducing the fear and stress during pregnancy and is effective for improving self-efficacy in pregnant women (3). Creating effective educational opportunities with a focus on training non-pharmacological methods of pain relief to pregnant women helps strengthen positive attitudes towards childbirth as a physiological phenomenon rather than a purely medical event and will result in empowering them to cope with fear of childbirth (7). The e-learning program in addition to raising mothers' level of knowledge and satisfaction saves time and expenses as well.
In the present study, education significantly increased the level of knowledge in the software group (5.48 units compared to the control group after the intervention) and booklet group (3.38 units compared to the control group after the intervention). Also, the knowledge level in the software group was also significantly higher than the booklet. Kuo et al conducted a study, in which the level of knowledge in the e-learning and control groups was significantly different 2 weeks after the training to the extent that knowledge score in the intervention and the control groups increased 7.2 and 1.7 times, respectively (15). In the study of Huang et al, the score of awareness of breastfeeding and the score of attitude towards the breastfeeding in the intervention group increased from 14.7 to 19.2 and from 94 to 103, respectively and there was a significant difference between the 2 groups in terms of level of awareness and attitude towards breastfeeding (12). The results of the present study are consistent with above studies. Several evidences have shown that software training can be more effective in increasing people's level of awareness and knowledge than traditional training. In a meta-anal- 
Table 2. Comparison of Knowledge of the Management of Labor Pain Before and After the Intervention Between Study Groups

\begin{tabular}{lcc}
\hline Groups & $\begin{array}{c}\text { Before Intervention } \\
\text { Mean (SD) }\end{array}$ & $\begin{array}{c}\text { After Intervention } \\
\left.\text { Mean }^{\text {(SD }}\right)^{a}\end{array}$ \\
\hline Software $(\mathrm{n}=50)$ & $1.6(0.8)$ & $9.0(2.0)$ \\
Booklet $(\mathrm{n}=51)$ & $1.4(0.6)$ & $6.9(1.9)$ \\
Control $(\mathrm{n}=52)$ & $1.6(0.6)$ & $3.5(1.3)$ \\
$P$ value & 0.288 & $<0.001$ \\
\hline Compare Groups & AMD $^{\mathrm{b}}(\mathbf{9 5 \%} \mathrm{Cl}) ; \boldsymbol{P}$ & AMD $^{\text {b }(95 \% \mathrm{Cl}) ; \boldsymbol{P}}$ \\
\hline Software with booklet & $0.2(0.1$ to 0.4$) ; 0.169$ & $2.1(1.2$ to 2.9$) ;<0.001$ \\
Software with control & $0.0(-0.2$ to 0.3$) ; 0.973$ & $5.5(4.6$ to 6.3$) ;<0.001$ \\
Booklet with control & $-0.2(-0.4$ to 0.1$) ; 0.176$ & $3.4(2.5$ to 4.2$) ;<0.001$
\end{tabular}

For comparison groups before intervention, one-way ANOVA was used and for comparison after intervention groups, ANCOVA was used.

${ }^{a}$ Mean (standard deviation); ${ }^{\text {b }}$ Adjusted mean difference (CI 95\%).

ysis published in 2006, it was shown that e-learning was effective $6 \%$ or more than face to face training in promoting knowledge (13). Mohamadirizi et al highlighted that e-learning package and pamphlets can raise awareness level in women after childbirth, thus, planning and implementing such training as an effective training is recommended (11).

In our country, prenatal educations are provided mostly in the form of lectures and in a very short time. Active methods often exert a greater influence on audiences so that the ancient Greeks believed that conversations and mass communication have a greater impact on the audience. Studies have shown that verbal training, along writing training is better than the verbal training alone (17). In fact, in e-learning (multimedia), written information along with the words and animations can be placed at the disposal of individuals at home or during traveling and at any time and, when necessary, be printed, which is one of the most important advantages of this method (15). It is reported that knowledge and awareness improves the management of labor pain and computer-based training programs can be effective in increasing pregnant women's level of awareness and knowledge about childbirth and pain-compatible behaviors (18).

Considering that in the booklet and software groups, people take responsibility of their own learning, it seems that there is a deeper learning thereby increasing the level of knowledge and awareness. Also, this education method, as an independent educational method, could have a potential effect in achieving the intended educational objectives.

The strengths of this study included observing all clinical trials principles, including random allocation and allocation concealment. Also, comparison of the use of modern teaching method with a traditional method was another strength point of this study. One of the limitations of this study was the possibility of forgetting to study the training packages, which was controlled by the weekly telephone contact made by the researcher. It is recommended that further studies in this field to be performed using other modern teaching methods, including the Internet.

\section{Conclusion}

The results showed that e-learning method raised pregnant women's level of knowledge regarding labor pain management, which plays a key role in the choice of delivery method and reducing the demand for cesarean section. E-Learning, because of its interactive nature, self-guidance, flexibility, lack of time and place constraints, can resolve some of the problems exist in the country for childbirth preparation classes and enhances and enriches training programs.

\section{Ethical Issues}

After approving the project and obtaining the ethics code from the ethics committee of Tabriz University of Medical Sciences (TBZMED.REC.1394.414), the trial was registered in the Iranian Registry of Clinical Trials website (identifier: IRCT2015072110324N24).

\section{Conflict of Interests}

The authors declare no conflict of interests.

\section{Financial Support}

This article is a result of a student thesis, which was sponsored by Tabriz University of Medical Sciences.

\section{Acknowledgments}

The researcher and his colleagues sincerely appreciate the vice chancellor of research of Tabriz University of Medical Sciences, head and personnel of healthcare centers of the city of Miandoab. Also, all pregnant women who helped us with great passion at all stages of our research, are appreciated.

\section{References}

1. Hosseininasab SD, Taghavi S, Ahmadian S. The effectiveness of prenatal education in decreasing the childbirth pain and anxiety. Med J Tabriz Univ Med Sci Health Serv. 2010;31(4):24-30. [Persian].

2. Mehdizadeh A, Roosta F, Kamali Z, Khoshgoo N. Evaluation of the effectiveness of antenatal preparation for child birth course on the health of the mother and the newborn. Razi J Med Sci. 2003;10(35):455-461.

3. Fabian HM, Radestad IJ, Waldenstrom U. Childbirth and parenthood education Classes in Sweden. Women's opinion and possible outcomes. Acta Obstet Gynecol Scand. 2005;84(5):436-43. doi:10.1111/j.0001-6349.2005.00732.x.

4. Sadeghi T, Heidari S, Bakhshi H. Comparison the lecture and E-learning training methods on knowledge of nurses participating in Continuing Medical Education (CME) programs in Rafsanjan University of Medical Sciences. Biannual Journal of Medical Education. 2014;2(1):59-64. [Persian].

5. Gharebaghi S, Soltan Mohammadi Z. Discussion learning activity a novel approach to virtual education. Iranian Journal of Educational Strategies. 2010;3(1):35-39. [Persian].

6. Khademian Z, Maghareei M, Shokranian N. Comparison of the effect of face to face teaching and the educational booklet on the patient's learning after urologic surgical procedures. J Nurs Educ. 2012;1(1):70-77. 
7. Mazani M, Hamidzadeh Arbabi Y, Nemati A, Mashoufi M, Mahdavi R. Comparing the effectiveness of attendance and nonattendance education of health workers on knowledge of mothers and anthropometric changes of infants. J Ardabil Univ Med Sci. 2012;3(1):74-86. [Persian].

8. Khanjani N, Jamshidi V. The strengths and shortcomings of the first distance learning MPH course at Kerman medical university from the students' viewpoint: a qualitative study. Iranian J Med Educ. 2011;11(4):318-331. [Persian].

9. Farshi M, Babatabar Darzi H, Mahmoudi H, Mokhtari Nouri J. Comparison of nursing care learning in airevacuation and transport by lecture and e-learning methods. J Mil Med. 2012;14(1):27-31. [Persian].

10. Siavash Vahabi Y, Tadrisi SD, Ghayyem S, Ebadi A, Daneshmandi M, Saghafi Nia M. Comparing the effect of triage lucation in lecture and multimedia software on nurses learning. Iran J Criti Care Nurs. 2011;4(1):7-12.

11. Mohamadirizi S, Bahadoran P, Fahami F. Comparison between the impacts of e-learning and booklet education on nulliparous women's satisfaction about postpartum care. Iran J Obstet Gynecol Infertil. 2013;16(61):1-8. doi:10.22038/ijogi.2013.1634.

12. Huang MZ, Kuo SC, Avery MD, Chen W, Lin KC, Gau ML. Evaluating effects of a prenatal web-based breastfeeding education programme in Taiwan. J
Clin Nurs. 2007;16(8):1571-1579. doi:10.1111/j.13652702.2006.01843.x.

13. Sitzmann T, Kraiger K, Stewart D, Wisher R. The comparative effectiveness of web-based and classroom instruction: a meta-analysis. Personnel Psychology. 2006;59(3):623-664. doi:10.1111/j.1744-6570.2006.00049.x.

14. Lin SS, Chien LY, Tai CJ, Lee CF. Effectiveness of a prenatal education programme on breastfeeding outcomes in Taiwan. J Clin Nurs. 2008;17(3):296-303. doi:10.1111/ j.1365-2702.2006.01927.x

15. Kuo SC, Chen YS, Lin KC, Lee TY, Hsu CH. Evaluating the effects of an Internet education programme on newborn care in Taiwan. J Clin Nurs. 2009;18(11):1592-1601. doi:10.1111/j.1365-2702.2008.02732.x.

16. Sasito T, Halmesmaki E. Fear of childbirth: a neglected dilemma. Acta Obstet Gynecol Scand. 2003;82(3):201-208. doi:10.1034/j.1600-0412.2003.00114.x

17. Langkamp DL, Hoshaw-Woodard S, Boye ME, Lemeshow S. Delay in receipt of immunizations in low-birthweight children: a nationally representative sample. Arch Pediatr Adolesc Med. 2006;155(2):167-172. doi:10.1001/ archpedi.155.2.167.

18. Amoshahi A, Safaei Moghadam M. Vaginal Delivery Without Pain. Isfahan: Naghsh Negin Publication; 2007:38. [Persian].

Copyright (c) 2017 The Author (s); This is an open-access article distributed under the terms of the Creative Commons Attribution License (http://creativecommons.org/licenses/by/4.0), which permits unrestricted use, distribution, and reproduction in any medium, provided the original work is properly cited. 